\title{
Numerical Simulation of Flow Behavior within a Venturi Scrubber
}

\author{
M. M. Toledo-Melchor, ${ }^{1}$ C. del C. Gutiérrez-Torres, ${ }^{1}$ J. A. Jiménez-Bernal, ${ }^{1}$ \\ J. G. Barbosa-Saldaña, ${ }^{1}$ S. A. Martínez-Delgadillo, ${ }^{2}$ H. R. Mollinedo-Ponce de León, ${ }^{3}$ \\ A. Yoguéz-Seoane, ${ }^{4}$ and A. Alonzo-García ${ }^{1}$ \\ ${ }^{1}$ Instituto Politécnico Nacional, SEPI ESIME Zacatenco, U.P. Adolfo López Mateos, Edificio 5, 3er. Piso, Col. Lindavista, \\ 07738 México, DF, Mexico \\ ${ }^{2}$ Departamento de Ciencias Básicas, Universidad Autónoma Metropolitana (Azcapotzalco), Avenida San Pablo 180, \\ 07740 México, DF, Mexico \\ ${ }^{3}$ Instituto Politécnico Nacional, UPIITA, Avenida IPN 2580, 07340 México, DF, Mexico \\ ${ }^{4}$ Quality Division, Atepoxco 74, Col. Repetición Insurgentes, 07020 México, DF, Mexico
}

Correspondence should be addressed to C. del C. Gutiérrez-Torres; cgutierrezt@ipn.mx

Received 26 December 2013; Accepted 11 April 2014; Published 29 June 2014

Academic Editor: Shaoyong Lai

Copyright (C) 2014 M. M. Toledo-Melchor et al. This is an open access article distributed under the Creative Commons Attribution License, which permits unrestricted use, distribution, and reproduction in any medium, provided the original work is properly cited.

\begin{abstract}
The present work details the three-dimensional numerical simulation of single-phase and two-phase flow (air-water) in a venturi scrubber with an inlet and throat diameters of 250 and $122.5 \mathrm{~mm}$, respectively. The dimensions and operating parameters correspond to industrial applications. The mass flow rate conditions were $0.483 \mathrm{~kg} / \mathrm{s}, 0.736 \mathrm{~kg} / \mathrm{s}, 0.861 \mathrm{~kg} / \mathrm{s}$, and $0.987 \mathrm{~kg} / \mathrm{s}$ for the gas only simulation; the mass flow rate for the liquid was $0.013 \mathrm{~kg} / \mathrm{s}$ and $0.038 \mathrm{~kg} / \mathrm{s}$. The gas flow was simulated in five geometries with different converging and diverging angles while the two-phase flow was only simulated for one geometry. The results obtained were validated with experimental data obtained by other researchers. The results show that the pressure drop depends significantly on the gas flow rate and that water flow rate does not have significant effects neither on the pressure drop nor on the fluid maximum velocity within the scrubber.
\end{abstract}

\section{Introduction}

The stricter environmental laws enforced nowadays require developing more efficient techniques and devices to remove diluted particles from gas flows [1]. Current alternatives to control particle emission sources are limited, especially regarding the prevention of particle generation which is normally based on combustible substitution.

The most common applied strategy to reduce particle emission and/or improve particle collection efficiency is either process modification or its optimization [2].

In many industries, fine particles' presence is a source of concern because they represent risks for some industrial processes as well as human health. In textile industry particularly, the presence of fiber dust is a real health hazard for textile workers. Besides fiber dust, lubricant oil fogs are a real problem in textile industry because they contribute to obstruct filtering systems.

Therefore, the use of wet scrubbers is a valid alternative to dry filters or cyclones, which are almost always the first option for particle removal [3]. Collection efficiency for wet scrubbers varies according to particle size distribution carried by a gas stream. In general, the collection efficiency of scrubbers decreases when particle size decreases [4].

Due to it, to obtain higher collection efficiency, it is necessary to increase power consumption. To reach a determined efficiency, power required increases as particle diameter decreases [5].

One of the most efficient wet particle collectors is the venturi scrubber [6]. This device has an atomization system 
TABLE 1: Geometry v175 details.

\begin{tabular}{lc}
\hline \multicolumn{2}{c}{ Venturi dimensions $(\mathrm{mm})$} \\
\hline Inlet and outlet diameter $\left(d_{1}\right)$ & 250 \\
Throat diameter $\left(d_{2}\right)$ & 122.5 \\
Converging length $\left(l_{1}\right)$ & 212.6 \\
Throat length $\left(l_{2}\right)$ & 300 \\
Diverging length $\left(l_{3}\right)$ & 742.95 \\
Converging angle $\left(\alpha_{1}\right)$ & $17^{\circ}$ \\
Diverging angle $\left(\alpha_{2}\right)$ & $5^{\circ}$ \\
\hline
\end{tabular}

TABLE 2: Geometry v17530 details.

\begin{tabular}{lc}
\hline \multicolumn{2}{c}{ Venturi dimensions $(\mathrm{mm})$} \\
\hline Inlet and outlet diameter $\left(d_{1}\right)$ & 325 \\
Throat diameter $\left(d_{2}\right)$ & 159.25 \\
Converging length $\left(l_{1}\right)$ & 276.4 \\
Throat length $\left(l_{2}\right)$ & 390 \\
Diverging length $\left(l_{3}\right)$ & 965.8 \\
Converging angle $\left(\alpha_{1}\right)$ & $17^{\circ}$ \\
Diverging angle $\left(\alpha_{2}\right)$ & $5^{\circ}$ \\
\hline
\end{tabular}

TABLE 3: Geometry v517 details.

\begin{tabular}{lc}
\hline \multicolumn{2}{c}{ Venturi dimensions $(\mathrm{mm})$} \\
\hline Inlet and outlet diameter $\left(d_{1}\right)$ & 250 \\
Throat diameter $\left(d_{2}\right)$ & 122.5 \\
Converging length $\left(l_{1}\right)$ & 742.95 \\
Throat length $\left(l_{2}\right)$ & 300 \\
Diverging length $\left(l_{3}\right)$ & 212.6 \\
Converging angle $\left(\alpha_{1}\right)$ & $5^{\circ}$ \\
Diverging angle $\left(\alpha_{2}\right)$ & $17^{\circ}$ \\
\hline
\end{tabular}

TABLE 4: Geometry v1717 details.

\begin{tabular}{lc}
\hline \multicolumn{2}{c}{ Venturi dimensions $(\mathrm{mm})$} \\
\hline Inlet and outlet diameter $\left(d_{1}\right)$ & 250 \\
Throat diameter $\left(d_{2}\right)$ & 122.5 \\
Converging length $\left(l_{1}\right)$ & 212.6 \\
Throat length $\left(l_{2}\right)$ & 300 \\
Diverging length $\left(l_{3}\right)$ & 212.6 \\
Converging angle $\left(\alpha_{1}\right)$ & $17^{\circ}$ \\
Diverging angle $\left(\alpha_{2}\right)$ & $17^{\circ}$ \\
\hline
\end{tabular}

and uses impaction interception and diffusion mechanisms to control particle and gas pollutant emissions to atmosphere [1].

Venturi scrubbers have been used for more than 50 years to collect particles [7]. They are mainly used in industrial plants to remove particles from gas streams and have been widely studied to understand their operation and model their performance [3].

This type of scrubber advantages are high collection efficiency for relatively small particles, low investment costs, dimensions, and the capacity of managing humid and corrosive gases.
TABLE 5: Geometry v55 details.

\begin{tabular}{lc}
\hline \multicolumn{2}{c}{ Venturi dimensions $(\mathrm{mm})$} \\
\hline Inlet and outlet diameter $\left(d_{1}\right)$ & 250 \\
Throat diameter $\left(d_{2}\right)$ & 122.5 \\
Converging length $\left(l_{1}\right)$ & 742.95 \\
Throat length $\left(l_{2}\right)$ & 300 \\
Diverging length $\left(l_{3}\right)$ & 742.95 \\
Converging angle $\left(\alpha_{1}\right)$ & $5^{\circ}$ \\
Diverging angle $\left(\alpha_{2}\right)$ & $5^{\circ}$ \\
\hline
\end{tabular}

Operation costs are their main disadvantage because the high pressure drop produced by their operation is directly translated in higher power consumption [8].

For a successful design of a venturi scrubber it is necessary to consider particle collection efficiency and pressure drop [1].

Venturi scrubbers have a convergent section, a narrow zone known as throat, and a divergent section. Gas velocity and turbulence are increased by the convergent section [1].

Although this kind of separators has been used in many industries and applications, and its operation has been studied along many years, its usefulness justifies the need of continuing studying its operation parameters, particle removal efficiency, and pressure drop. Recently, nuclear power plant applications of these devices have been explored theoretically and experimentally for iodine removal [9]. The capture of contaminated particles from a nuclear power plant using a venturi scrubber was also studied experimentally and a capture efficiency model was proposed [10], and a CFD simulation of particle removal efficiency that shows good agreement with experimental results has also been reported [11].

A novel design of venturi scrubbers was proposed to improve a desulphurization process using shuttle-shape bodies inside a rectangular duct that would be equivalent to several venturi scrubbers working in a parallel arrangement that improved dust collection and the desulphurization process [12].

The objective of this work is to analyze using computational fluid dynamics (CFD) the gas flow behavior within a venturi scrubber varying convergence and divergence angles as well as evaluate the effects of water flow on the pressure drop in a venturi scrubber.

\section{Materials and Methods}

A 3-dimensional geometry of a venturi scrubber was created to reproduce this device section of the experimental setup reported by Silva et al. [3]. This was carried out with the objective of validating numerical results. The computational domain was meshed using a 606500 elements grid [13]. The different section lengths of the studied scrubber $\left(l_{0}\right.$, $l_{1}$, and $l_{2}$ ) and the corresponding angles $\left(\alpha_{0}\right.$ and $\left.\alpha_{1}\right)$ are shown in Figure 1. Their dimensions are reported in Table 1. To distinguish this particular geometry in this work it is 


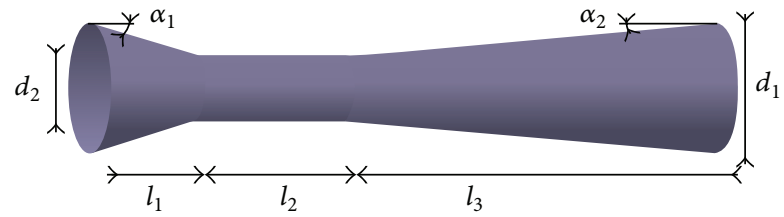

FIGURE 1: Venturi scrubber geometry v175.

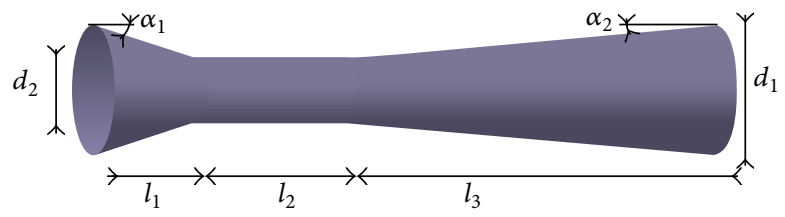

FIgURE 2: Venturi scrubber geometry v17530.

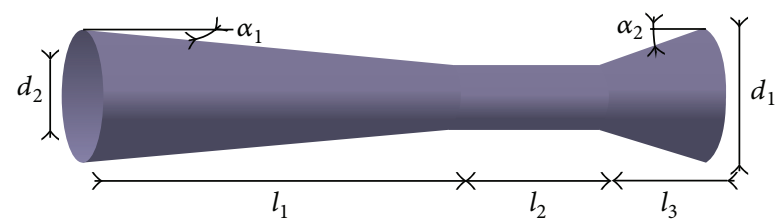

FIGURE 3: Venturi scrubber geometry v517.

designated v175 geometry because it has a convergence angle of $17^{\circ}$ and a divergence angle of $5^{\circ}$.

Numerical simulation of the flow was performed using software Fluent 12.1. The fluid used was air behaving as an incompressible gas. Steady state and three-dimensional domain conditions were stated. Mass flow rate inlet conditions from $0.483 \mathrm{~kg} / \mathrm{s}$ to $0.987 \mathrm{~kg} / \mathrm{s}$ were used. The mass conservation equation for the gas is shown as

$$
\frac{\partial \rho_{G}}{\partial t}+\nabla \cdot\left(\rho_{G} u_{G}\right)=0
$$

Gas properties were applied for standard conditions ( $1 \mathrm{~atm}$ and $288.16 \mathrm{~K}$ ). Turbulent flow was considered since Reynolds numbers calculated at venturi's inlet were from $1.37 \times 10^{5}$ to $2.81 \times 10^{5}$. Spalart-Allmaras turbulence model was used. No heat transfer existing between the gas and venturi's walls was assumed.

Figure 2 shows the v17530 geometry. This scrubber has the same converging and diverging angles as the v175 geometry. However, its length and diameters were increased $30 \%$ with respect to v175 scrubber in order to keep the same angle values. Its dimensions are shown in Table 2.

Furthermore, other configurations were established changing the converging and diverging angles to analyze their effects on pressure drop and gas velocity. Figure 3 shows venturi v517. It has a converging angle of $5^{\circ}$ and a diverging angle of $17^{\circ}$. Geometry dimensions are shown in Table 3.

Figure 5 shows geometry v55, which has the same converging and diverging angle $\left(5^{\circ}\right)$. Geometry details for this configuration are presented in Table 5. See also Figure 4 for geometry v1717 and its details in Table 4.

Numerical simulation results were initially validated using experimental data obtained by Silva et al. [3]. Figure 6

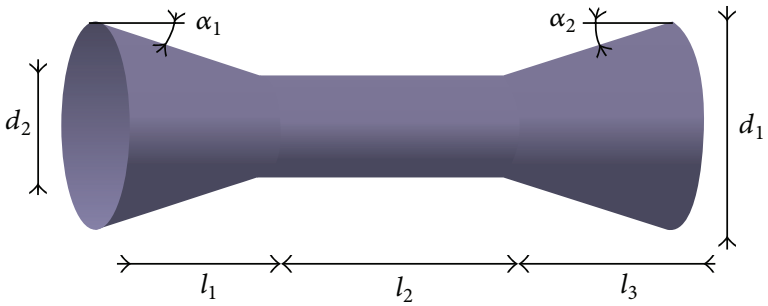

Figure 4: Venturi scrubber geometry v1717.

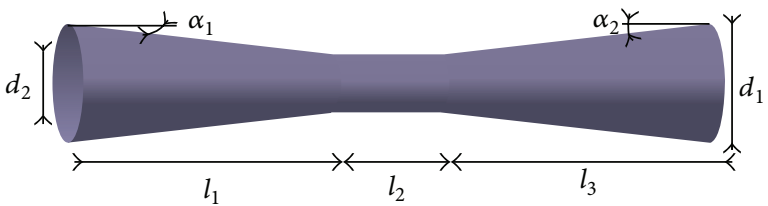

FIGURE 5: Venturi scrubber geometry v55.

shows the location of the pressure taps along the venturi for the experimental work. For presented numerical results pressures are reported at the same location.

\section{Results and Discussion}

Geometry v175 is the scrubber whose behavior was first simulated. Its dimensions are exactly the same as the ones reported by Silva et al. [3] in their reported experimental setup. Figure 7 shows the experimental data and the numerical results for four air mass flow rate conditions $(0.483 \mathrm{~kg} / \mathrm{s}$, $0.736 \mathrm{~kg} / \mathrm{s}, 0.861 \mathrm{~kg} / \mathrm{s}$, and $0.987 \mathrm{~kg} / \mathrm{s}$ ).

Numerical simulation using the alternative geometry configurations was performed as well to try to elucidate the effect of converging and diverging angles changes. Figure 8 shows manometric pressure distribution along pressure taps for a mass flow of $0.736 \mathrm{~kg} / \mathrm{s}$. Figures 9 and 10 show velocity contours at different cross-sections along the venturi for the same mass flow rate; velocity contours are reported in $\mathrm{m} / \mathrm{s}$.

In this work continuity residuals reached values of $1 \times$ $10^{-4}$, meanwhile velocity residuals reached values of $1 \times$ $10^{-7}$. A converged simulation was considered when residuals reached the aforementioned criteria and complied with mass conservation.

It can be observed in Figure 7 that both numerical and experimental data have similar trends. In both cases it is being observed that an increase in the gas flow rate increases pressure drop. There is a pressure drop in the converging section that is due to gas acceleration. In the throat section, pressure drop is only produced by friction. The largest part of this pressure drop (up to 70\%) is recovered in the diverging section. Therefore, nonrecovered energy is lost due to the friction between the gas and the wall.

From numerical results it was observed that maximum velocity values were not affected when converging and diverging angles were changed. However, angle modification does have significant effects on pressure values. 


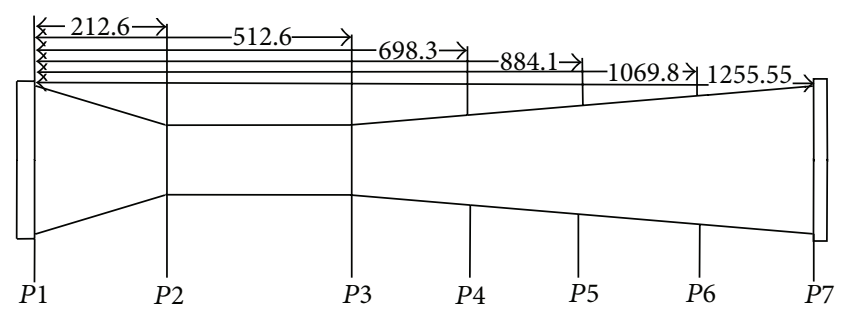

Figure 6: Pressure taps' location.

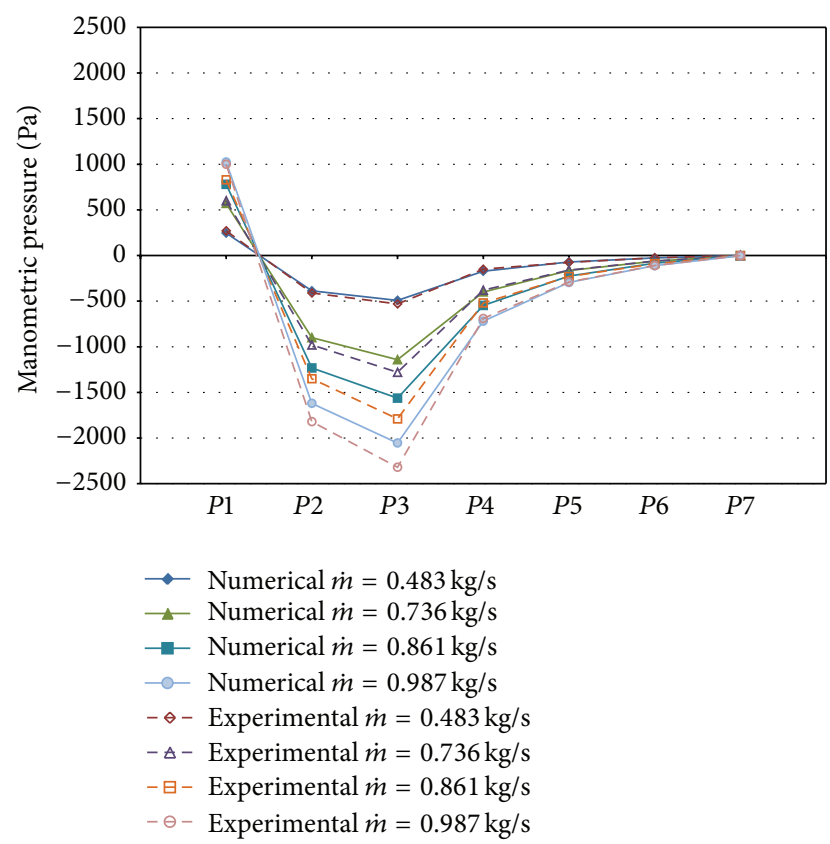

FIGURE 7: Manometric pressure within venturi scrubber.

Also in Figure 8 it is observed that all tested geometries have the same behavior, and the lowest manometric pressure value, at the end of the throat section no matter the diverging angle. Furthermore, geometries with the same diverging angle present very similar pressure values; therefore, it can be said that diverging angle values have a stronger effect on the scrubber pressure behavior than converging angle values.

Velocity contours agree with other researchers results [14]. As it was expected, contours show that fluid velocity increases as fluid passes through converging section reaching its maximum value at the throat section. Once the gas flows out the throat section, velocity decreases while the fluid passes through the diverging section of the venturi.

Table 6 shows the total pressure drop for every geometry configuration for a mass flow rate of $0.736 \mathrm{~kg} / \mathrm{s}(P 1-P 7)$ and the pressure drop in the throat section $(P 2-P 3)$. As previously mentioned, the diverging angle has a very significant effect on pressure values and total pressure drop. Geometry configurations with the same values of diverging angle have similar total pressure drop values. It is also observed that increasing

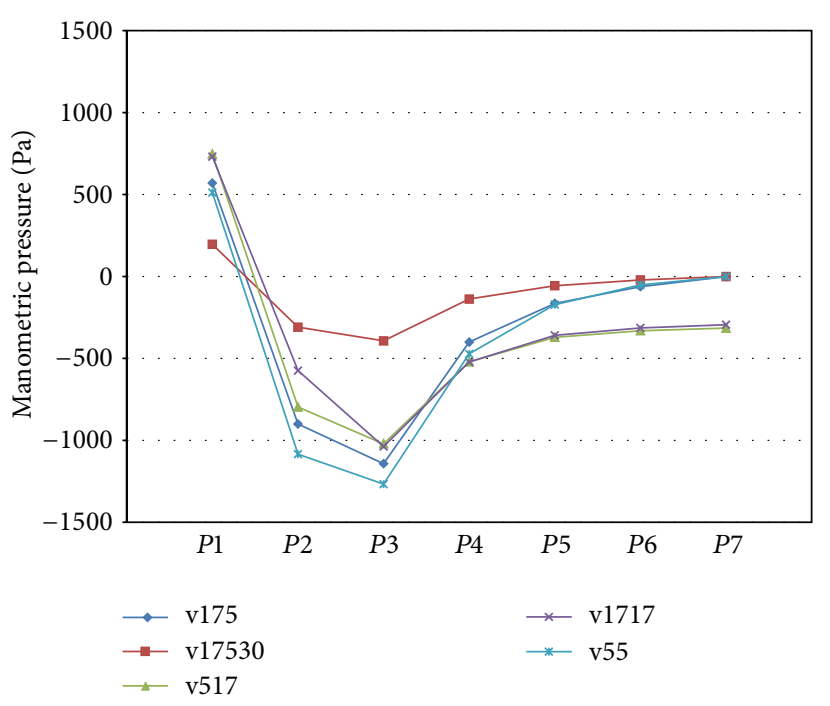

Figure 8: Manometric pressure for an air mass flow rate of $0.736 \mathrm{~kg} / \mathrm{s}$.



FIGURE 9: Cross-section velocity contour for venturi v175.

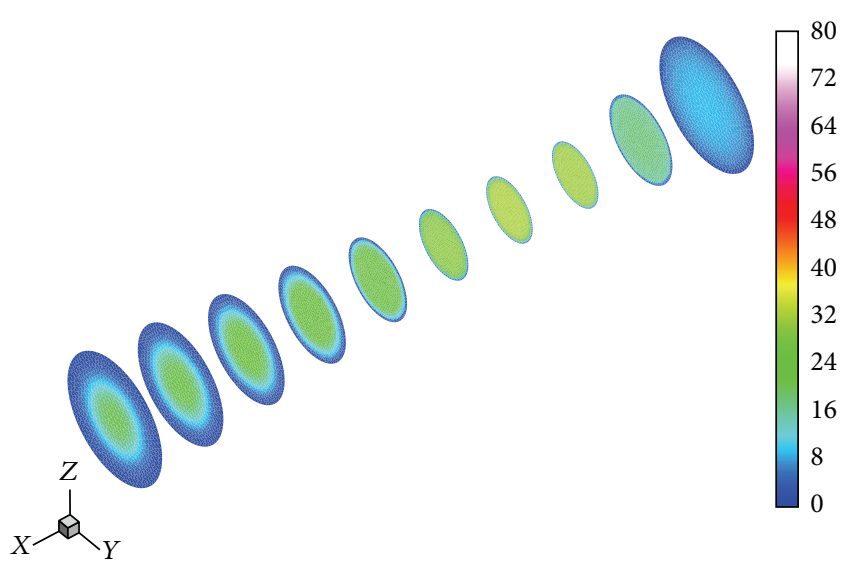

FIGURE 10: Cross-section velocity contour for v17530. 


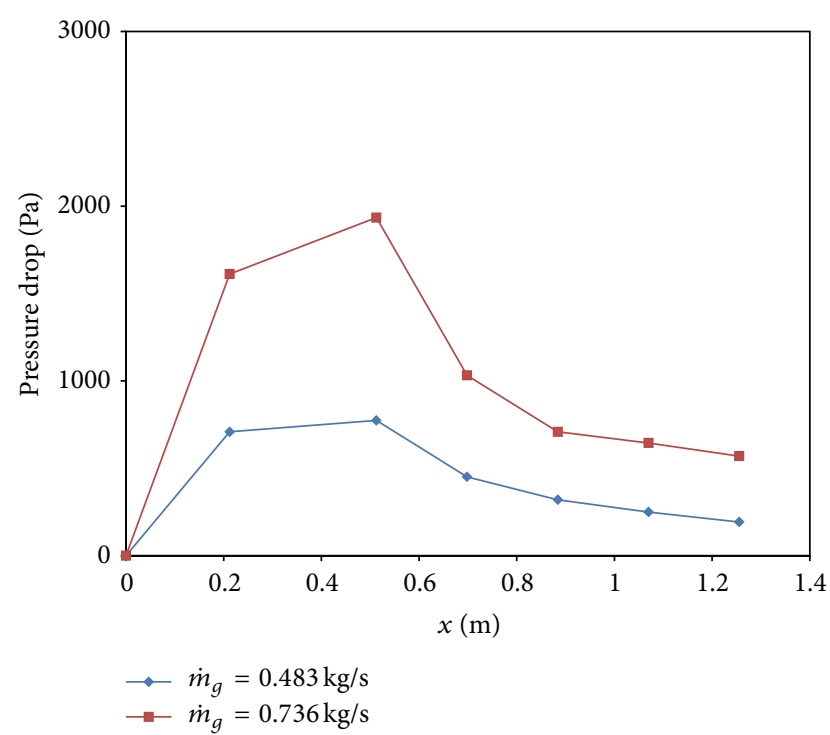

FIGURE 11: Experimental pressure drop results for water mass flow rate of $0.013 \mathrm{~kg} / \mathrm{s}$ [3].

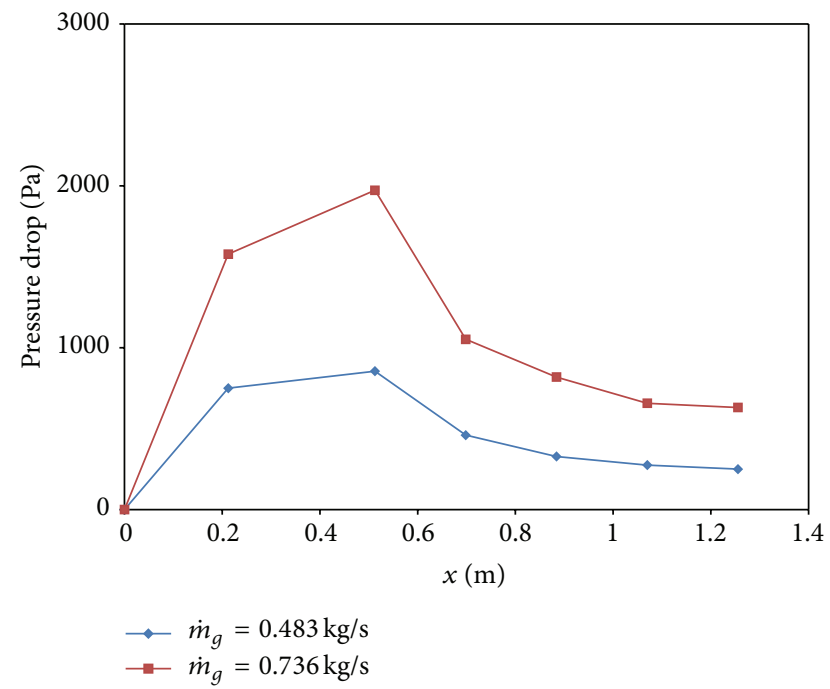

FIGURE 12: Numerical pressure drop results for water mass flow rate of $0.013 \mathrm{~kg} / \mathrm{s}$.

the length of different sections and diameter values by $30 \%$ decreases the pressure drop value by $65.5 \%$.

It can also be observed that when the diverging angle increases, so does the total pressure drop. The largest total pressure drop (1013.97 Pa) was obtained with the v517 geometry. However, only $21.12 \%$ of this pressure drop takes place within the throat section.

Although geometry v55 has the lowest total pressure drop $(512.7 \mathrm{~Pa})$, the throat section pressure drop represents $36.67 \%$ of the total one. Therefore, $63.33 \%$ of the total pressure

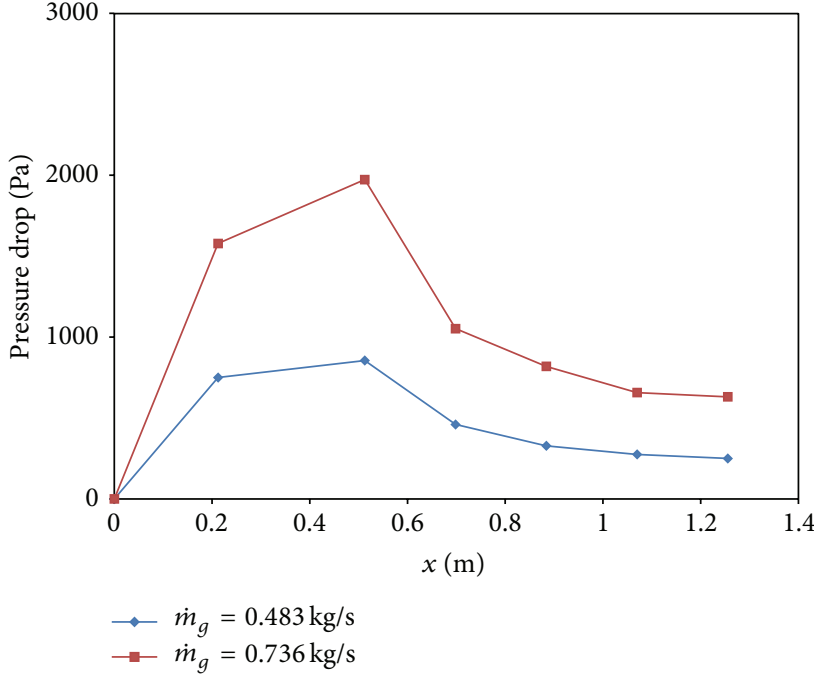

Figure 13: Experimental pressure drop results for water mass flow rate of $0.038 \mathrm{~kg} / \mathrm{s}$ [3].

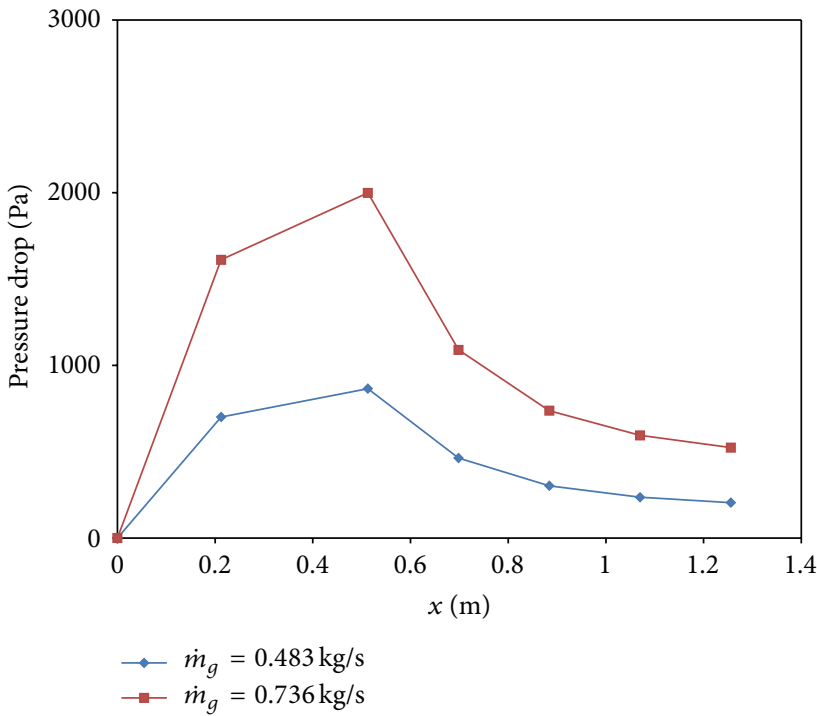

FIGURE 14: Pressure drop results for water mass flow rate of $0.038 \mathrm{~kg} / \mathrm{s}$.

drop value takes place within the converging and diverging sections.

It is desirable to have the largest possible pressure drop within the throat section and, at the same time, have the lowest possible total pressure drop because it is at the throat section where phase-mixing takes place. Taking this into consideration, the best behavior is found in geometry v175 because its throat section pressure drop represents $42.31 \%$ of the total.

For two-phase flow two gas mass flow rate values $(0.483 \mathrm{~kg} / \mathrm{s}$ and $0.736 \mathrm{~kg} / \mathrm{s})$ and two water mass flow rate 


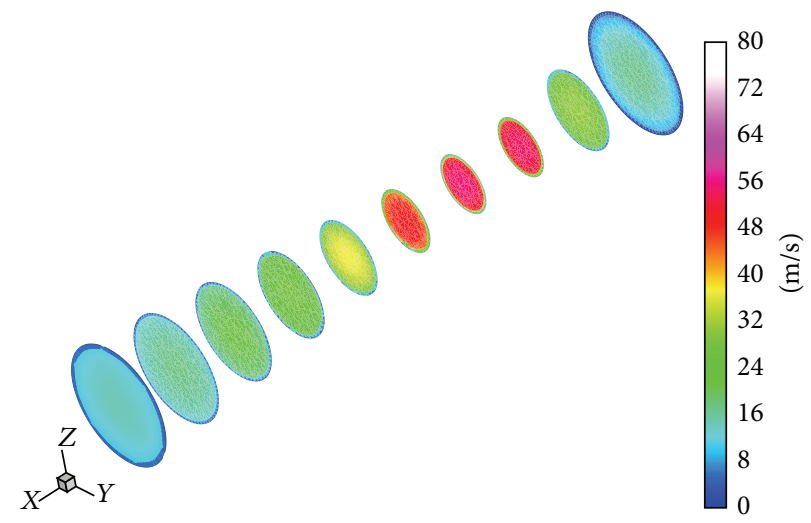

FIGURE 15: Cross-section velocity contours for an air flow rate of $0.736 \mathrm{~kg} / \mathrm{s}$ and a mass flow rate of $0.013 \mathrm{~kg} / \mathrm{s}$.



FIgURE 16: Cross-section velocity contours for an air flow rate of $0.736 \mathrm{~kg} / \mathrm{s}$ and a mass flow rate of $0.038 \mathrm{~kg} / \mathrm{s}$.

values $(0.013 \mathrm{~kg} / \mathrm{s}$ and $0.038 \mathrm{~kg} / \mathrm{s})$ were simulated for the v175 geometry (Figure 11). Liquid phase was introduced within the scrubber $5 \mathrm{~cm}$ upstream the converging section using four equidistant pipes placed at $90^{\circ}$ with respect to scrubber inlet pipe surface. The obtained data were compared to experimental data reported by Silva el al. [3]. The numerical results obtained using the same mass flow rate values for gas and liquid used experimentally are shown in Figure 12.

Both figures show that numerical results have a trend similar to experimental ones. The same can be observed in Figures 13 and 14 where experimental and numerical results are presented respectively for a water mass flow rate of $0.038 \mathrm{~kg} / \mathrm{s}$.

Figure 15 shows cross-section velocity contours for an air mass flow rate of $0.736 \mathrm{~kg} / \mathrm{s}$ and a water mass flow rate $0.013 \mathrm{~kg} / \mathrm{s}$ (geometry v175). Meanwhile, Figure 16 shows cross-section velocity contours for an air mass flow rate of $0.736 \mathrm{~kg} / \mathrm{s}$ and a water mass flow rate $0.038 \mathrm{~kg} / \mathrm{s}$ for the same geometry. When comparing both figures to Figure 9 (same geometry and air mass flow rate), it can be observed that for the three cases the maximum velocity value is found within the throat section and that water presence does not produce changes on the maximum velocity values. However, velocity distributions in the diverging section are modified.

\section{Conclusions}

Pressure drop data for a venturi scrubber obtained from a numerical simulation are presented. The effect of gas velocity for four different air mass flow rate values $(0.483 \mathrm{~kg} / \mathrm{s}$, $0.736 \mathrm{~kg} / \mathrm{s}, 0.861 \mathrm{~kg} / \mathrm{s}$, and $0.987 \mathrm{~kg} / \mathrm{s}$ ) and five geometries were analyzed. Numerical results are in good agreement with experimental ones. The largest pressure drop was obtained with the largest mass flow rate. However, pressure drop does not increase proportionally to mass flow rate increase.

The first run tried to reproduce numerically the experimental results obtained by Silva et al. [3] where a maximum error value of $10.7 \%$ was obtained. This was calculated at $P 3$ since it is a point where major velocity changes took place. When geometry dimensions were increased by $30 \%$, maintaining the same converging and diverging angles the velocity at the throat section decreased by $40.9 \%$ and pressure drop decreased by $65.5 \%$.

When converging and/or diverging angles were changed there were not significant modifications on maximum velocity values within the venturi. However, these changes do have significant effects on pressure values. It was observed that geometries with the same diverging angles have very similar total pressure drop values. This is due to the energy recovery 
TABLE 6: Total pressure drop.

\begin{tabular}{lcc}
\hline Geometry & $\begin{array}{c}\text { Total pressure } \\
\text { drop }(\mathrm{Pa})\end{array}$ & $\begin{array}{c}\text { Throat section pressure } \\
\text { drop (Pa) }\end{array}$ \\
\hline v175 & 571.29 & 241.74 \\
v17530 & 196.76 & 83.36 \\
v517 & 1013.97 & 224.34 \\
v1717 & 995.9 & 463.25 \\
v55 & 512.7 & 182.92 \\
\hline
\end{tabular}

that takes place at the diverging section. The variation of converging angles does not seem to have an effect neither on the velocity values nor on the pressure drop.

Furthermore, when liquid was introduced to the computational domain, it was found that the liquid mass flow rate does not affect the total pressure drop.

\section{Conflict of Interests}

The authors declare that there is no conflict of interests regarding the publication of this paper.

\section{References}

[1] S. Viswanathan, "Examination of liquid film characteristics in the prediction of pressure drop in a Venturi scrubber," Chemical Engineering Science, vol. 53, no. 17, pp. 3161-3175, 1998.

[2] R. A. Corbitt, Standard Handbook of Environmental Engineering, McGraw-Hill, 2004.

[3] A. M. Silva, J. C. F. Teixeira, and S. F. C. F. Teixeira, "Experiments in a large-scale venturi scrubber. Part I: pressure drop," Chemical Engineering and Processing: Process Intensification, vol. 48, no. 1, pp. 59-67, 2009.

[4] EPA, Air Pollution Control Cost Manual, 6th edition, 2002.

[5] R. H. Perry and D. W. Green, Chemical Engineers Handbook, McGraw-Hill, 7th edition, 2003.

[6] R. W. K. Allen and A. van Santen, "Designing for pressure drop in Venturi scrubbers: the importance of dry pressure drop," The Chemical Engineering Journal and the Biochemical Engineering Journal, vol. 61, no. 3, pp. 203-211, 1996.

[7] R. H. Boll, "Particle collection and pressure drop in venturi scrubbers," Industrial and Engineering Chemistry, vol. 12, no. 1, pp. 40-50, 1973.

[8] N. V. Ananthanarayanan and S. Viswanathan, "Predicting the liquid flux distribution and collection efficiency in cylindrical Venturi scrubbers," Industrial and Engineering Chemistry Research, vol. 38, no. 1, pp. 223-232, 1999.

[9] M. Ali, C. Yan, Z. Sun, H. Gu, and J. Wang, "Study of iodine removal efficiency in self-priming venturi scrubber," Annals of Nuclear Energy, vol. 57, pp. 263-268, 2013.

[10] M. Ali, C. Yan, Z. Sun, H. Gu, and K. Mehboob, "Dust particle removal efficiency of a venturi scrubber," Annals of Nuclear Energy, vol. 54, pp. 178-183, 2013.

[11] M. Ali, C. Yan, Z. Sun, J. Wang, and H. Gu, "CFD simulation of dust particle removal efficiency of a venturi scrubber in CFX," Nuclear Engineering and Design, vol. 256, pp. 169-177, 2013.

[12] T. Mi and X. M. Yu, "Dust removal and desulphurization in a novel venturi scrubber," Chemical Engineering and Processing: Process Intensification, vol. 62, pp. 159-167, 2012.
[13] M. Toledo-Melchor, Comportamiento del flujo en un separador tipo lavador mediante simulación numérica [M.S. thesis], SEPIESIME-Instituto Politecnico Nacional, México, México, 2011.

[14] C. Goniva, Ž. Tukovic, C. Feilmayr, T. Bürgler, and S. Pirker, "Simulation of offgas scrubbing by a combined EulerianLagrangian model," in Proceedings of the 7th International Conference on CFD in the Minerals and Process Industries (CSIRO '09), Melbourne, Australia, December 2009. 


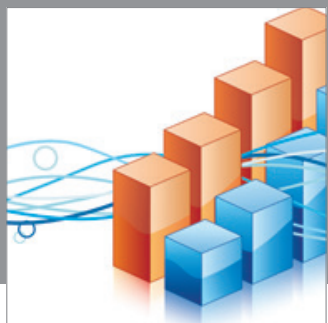

Advances in

Operations Research

mansans

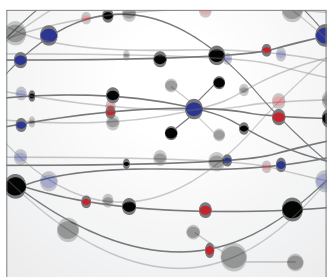

The Scientific World Journal
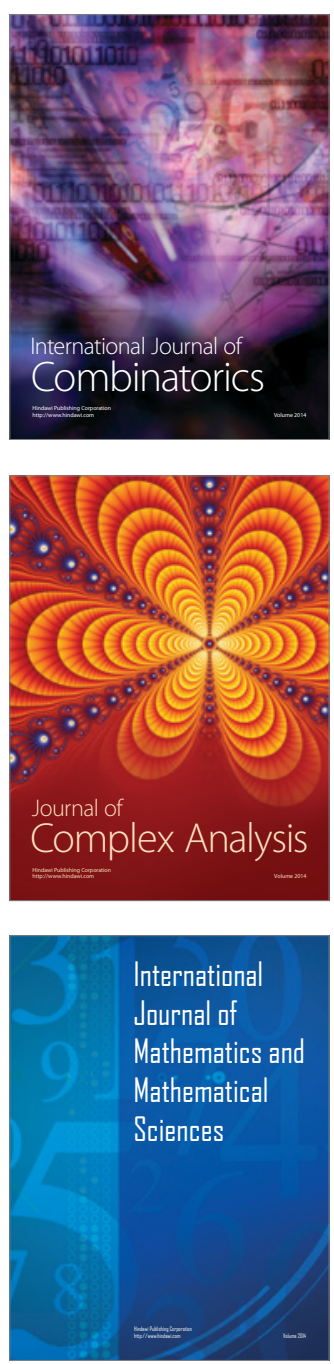
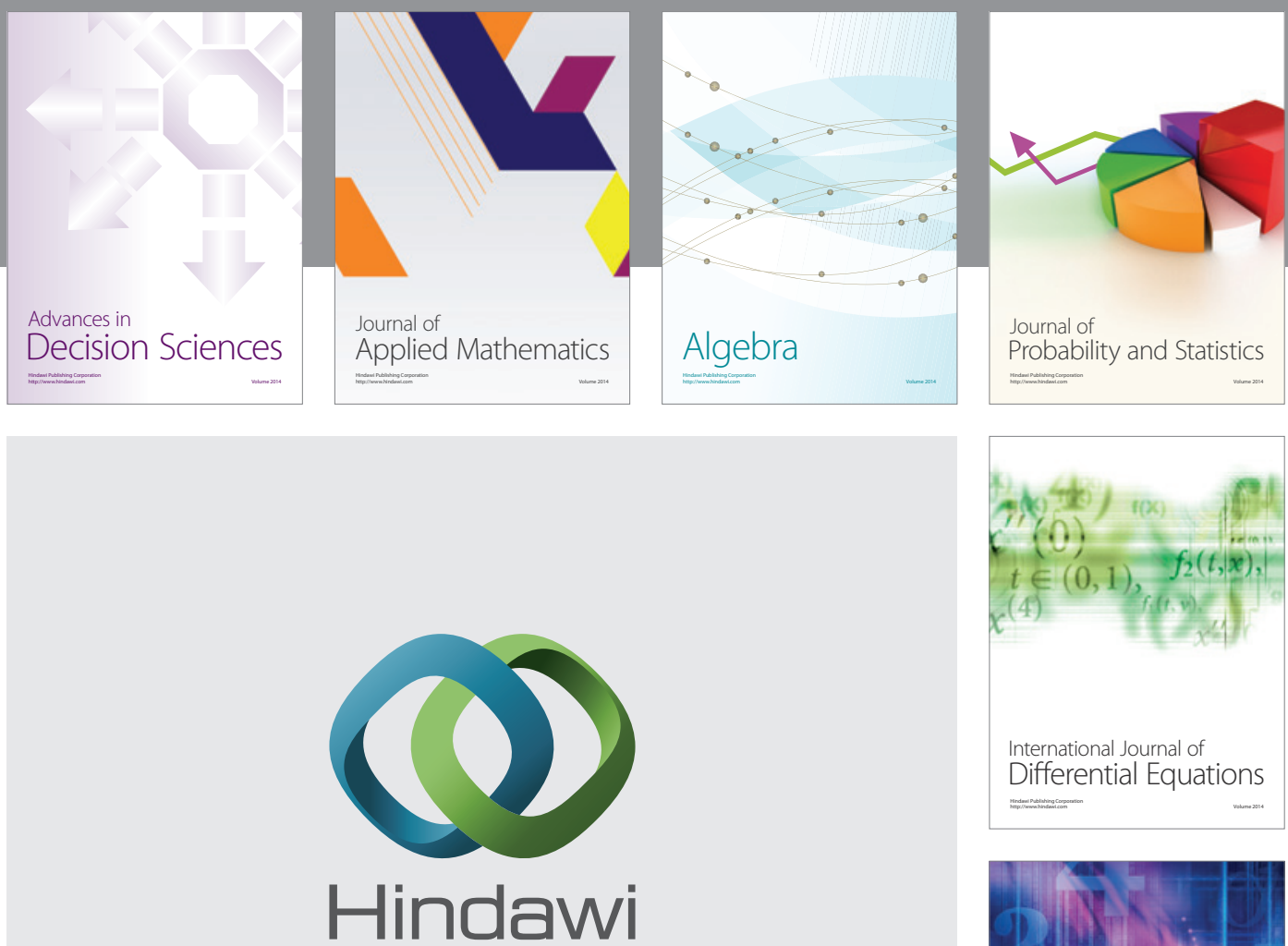

Submit your manuscripts at http://www.hindawi.com
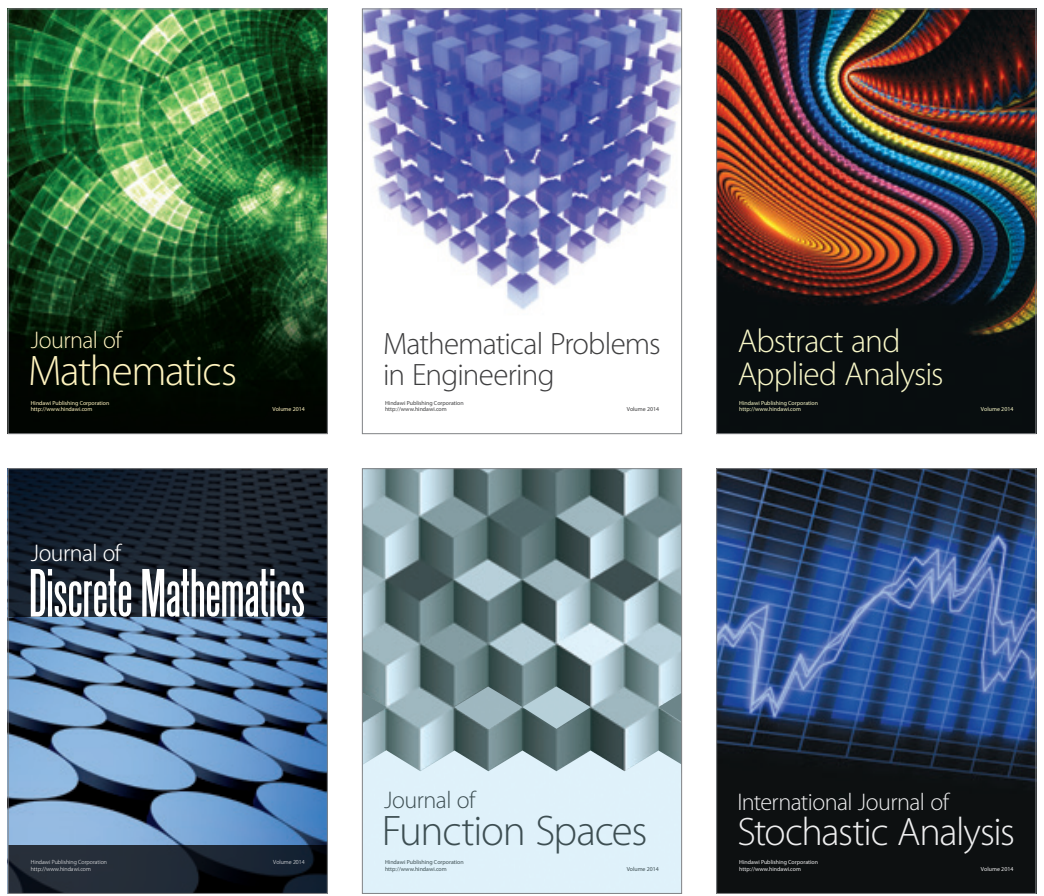

Journal of

Function Spaces

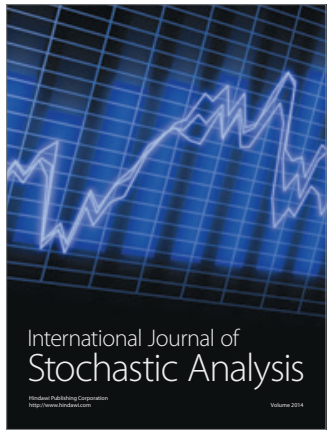

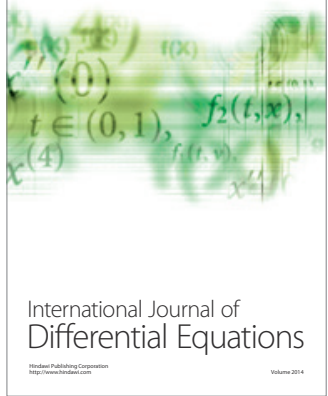
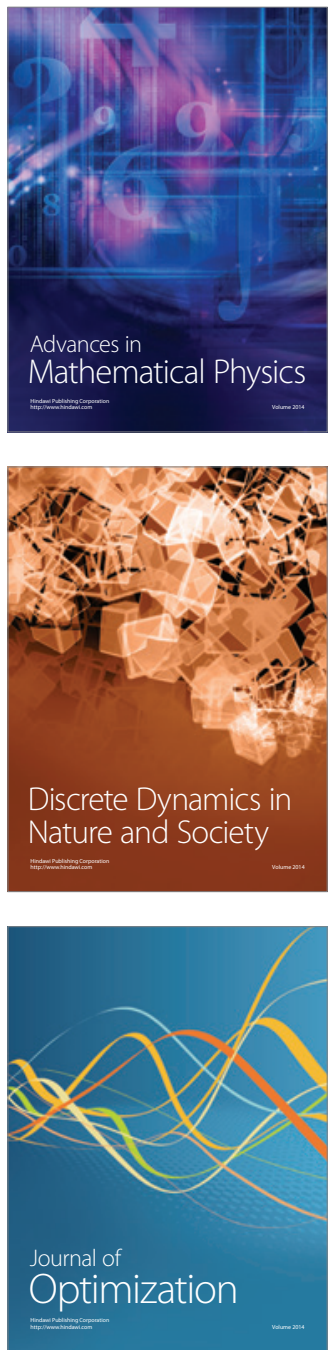